\title{
Robótica Educativa: Drones e Novas Perspectivas
}

Igor Yepes - IFFarroupilha - igor.yepes@iffarroupilha.edu.br Dante Augusto Couto Barone - PPGIE/UFRGS - barone@inf.ufrgs.br

Resumo: Este trabalho, apresenta um levantamento realizado visando identificar o uso de drones em atividades de robótica educativa em disciplinas STEM. Após ampla pesquisa bibliográfica, compreendendo estudos publicados de 2014 até 2018, confirmouse a quase ausência do uso dessa tecnologia na área pedagógica, limitando-se, na maioria dos casos, ao uso de drones como ferramentas para captura de imagens ou vídeos para subsidiar temas de disciplinas diversas, ou para ensino específico sobre drones. Contudo, verificou-se que a área comercial já detectou esse nicho e oferta algumas plataformas com drones contendo recursos interessantes, cabendo à área acadêmica desenvolver estudos que comprovem a viabilidade do uso pedagógico desses equipamentos bem como suas reais potencialidades e possibilidades.

Palavras-chave: drones, robótica educativa, disciplinas STEM.

\section{Educational Robotics: Drones and New Perspectives}

\begin{abstract}
This work presents a survey to identify the use of drones in educational robotics activities in STEM subjects. After extensive bibliographical research, covering published works from 2014 until 2018, it was identified the almost absence of the use of this technology in the pedagogical area, being limited, in most cases, to the use of drones as tools for capturing images or videos to give support to diverse subjects, or for teaching specifically over drones. However, the commercial area has detected this niche and offers some platforms with drones with interesting resources, touching to the academic area the development of studies that prove the feasibility of the pedagogical use of these equipments as well as their real potentialities and possibilities.
\end{abstract}

Keywords: drones, educational robotics, STEM subjects.

\section{Introdução}

Drone é um termo genérico utilizado para identificar uma aeronave não tripulada, podendo ter características autônomas ou ser controlada por um operador humano. Existem diversos tipos de drones e, gradualmente, vêm se difundindo para além da área militar, ganhando destaque em aplicações civis e tornando-se uma opção válida no cenário comercial atual. Essas aeronaves podem ir desde um veículo em escala controlado via rádio (planadores, helicópteros, dirigíveis, aviões, entre outros) a veículos tão sofisticados como aviões em tamanho real (Silva e Yepes, 2016).

Os quadrotores, tipo de drone com quatro propulsores independentes, são veículos aéreos, geralmente de pequena dimensão, com uma configuração de asa rotativa, constituída por quatro motores e seus respectivos propulsores que asseguram a sustentação em voo. A dinâmica de voo de um quadrotor é relativamente simples, como é possível verificar na Figura 1. De forma geral, em um drone com quatro asas rotativas (quadrotor) os motores 1 e 3 rodam no sentido anti-horário e os motores 2 e 4 rodam no sentido horário, isto porque os motores em rotação criam não só forças verticais responsáveis pela sustentação mas também forças horizontais que criam um movimento de rotação do quadrotor sobre o seu eixo central $\left(B_{z}\right)$. O fato de existir um par de motores rodando num sentido e outro par no sentido inverso, cria duas forças horizontais contrárias permitindo assim controlar o movimento de rotação do quadrotor sobre o seu 
eixo central aumentando a controlabilidade do ângulo Yaw em voo (movimento em torno do eixo vertical, perpendicular ao eixo longitudinal. Também chamado de guinada). $\mathrm{O}$ controle do ângulo Pitch (movimento em torno do eixo horizontal, perpendicular ao eixo longitudinal) e do Roll (movimento em torno do eixo horizontal, na direção do eixo longitudinal) são muito semelhantes bastando aumentar e diminuir a velocidade dos motores que se encontram nos cantos opostos da estrutura cruzada da aeronave. No caso do ângulo do Roll o controle é executado sobre os motores 1 e 3, e no ângulo do Pitch sobre os motores 2 e 4 . A altitude pode ser controlada aumentando ou diminuindo a velocidade dos quatro motores simultaneamente.

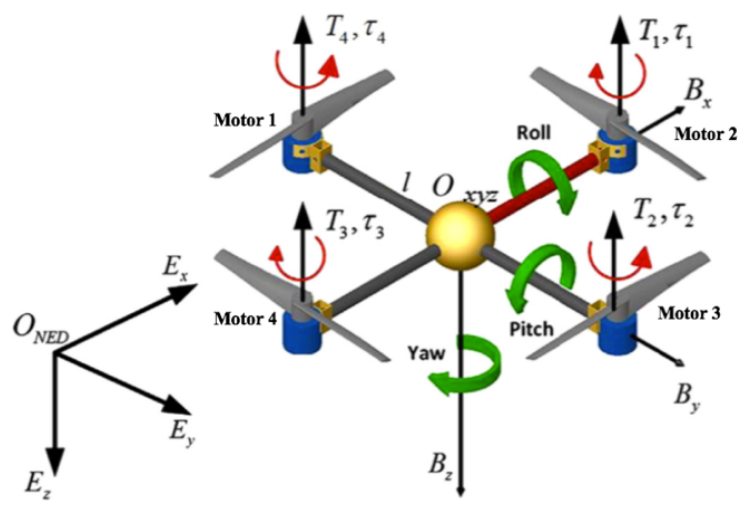

Figura 1 - Dinâmica do voo de um drone do tipo quadrotor adaptado de Zhao e Go (2014).

Dentre as possíveis tarefas que podem ser desempenhadas pelos drones, podem ser listadas as constantes no Quadro 1 (Ware, 2018; Hassanalian e Abdelkefi, 2017; Luppicini e So, 2016):

Quadro 1 - Algumas das possíveis aplicações de drones.

\begin{tabular}{|c|c|}
\hline Segurança & \\
\hline \multirow{4}{*}{$\begin{array}{l}\text { - Apoio tático; } \\
\text { - serviço de inteligência; } \\
\text { - controle de áreas sujeitas a atividades ilegais; } \\
\text { - reconhecimento e controle de áreas suspeitas de } \\
\text { atividades de narcotráfico; } \\
\text { - busca e auxílio em situações de resgate; } \\
\text { - investigação criminal e de acidentes; } \\
\text { - segurança patrimonial; } \\
\text { - monitoramento de trafego de veículos; } \\
\text { - avaliação de condições de rodovias e linhas } \\
\text { férreas; } \\
\text { - monitoramento contínuo do incêndio e } \\
\text { verificação da extensão de danos e movimento } \\
\text { do fogo; } \\
\text { - avaliação de zonas de desastres. }\end{array}$} & $\begin{array}{l}\text { - } \text { Inspeção de locais de difícil acesso; } \\
\text { - } \text { busca e localização de falhas em linhas de } \\
\text { energia, comunicação, gasodutos, oleodutos } \\
\text { etc.; } \\
\text { - } \\
\text { - } \\
\text { monspeção de linhas de transmissão; } \\
\text { possibilitando uma melhor fiscalização de obras } \\
\text { (edifícios, praças, pontes, viadutos e estradas). }\end{array}$ \\
\hline & Agropecuária \\
\hline & $\begin{array}{l}\text { - Agricultura de precisão; } \\
\text { - monitoramento de rebanhos e pastagens }\end{array}$ \\
\hline & Serv \\
\hline Meio Ambiente & \multirow[b]{2}{*}{$\begin{array}{l}\text { - } \text { Transporte pessoal; } \\
\text { - } \text { transporte de produtos; } \\
\text { - } \text { educação; } \\
\text { - } \text { fotografia aérea e filmagem (cinema, } \\
\text { comerciais, eventos, notícias etc.); } \\
\text { - } \text { fotos e vídeos para a área de arqueologia, } \\
\text { geologia etc; } \\
\text { - } \text { fotografia e filmagem não comerciais; } \\
\text { - lazer. }\end{array}$} \\
\hline $\begin{array}{l}\text { - Monitoramento de áreas de preservação } \\
\text { permanente para auxiliar no controle ambiental } \\
\text { e ecológico (desmatamento, pesca ilegal, mata } \\
\text { ciliar, queimadas, etc.); } \\
\text { - monitoração de poluentes e poluição; } \\
\text { - georreferenciamento de pontos de difícil acesso; } \\
\text { - avaliação ambiental e de dano ambiental; } \\
\text { - meteorologia. }\end{array}$ & \\
\hline
\end{tabular}

Conforme o Quadro 1, já se vislumbra o uso de drones na área educativa, contudo, apesar do grande potencial apresentado por esse tipo de equipamento, esse uso é ainda 
bastante incipiente e limitado. Mesmo com o surgimento de equipamentos voltados à área de educação, sua inserção ainda é tímida no ambiente escolar. Em parte, pelos custos desse tipo de equipamento, pois ainda é caro estruturar um laboratório com drones. Há muitos drones de baixo custo, entretanto, a grande maioria reflete esse baixo custo na qualidade dos seus componentes e, consequentemente, na precisão dos equipamentos (geralmente de difícil manobrabilidade e baixa estabilidade) tornando-os impróprios para uso em aula. Equipamentos com maior estabilidade e precisão nos comandos tendem a ser bastante caros. Por outro lado, há o despreparo dos professores para uso dessa tecnologia e a falta de estudos balizadores e propostas metodológicas que utilizem drones como ferramenta de ensino.

\subsection{Drones na robótica educativa}

A Base Nacional Curricular Comum (BNCC) para o ensino médio, é o instrumento de gestão pedagógica que visa definir os conhecimentos essenciais aos quais todos os estudantes brasileiros têm o direito de ter acesso e se apropriar durante sua trajetória escolar, seja ela pública ou particular (Brasil, 2017). Contudo, segundo França e Tedesco (2017), diferente de outras iniciativas internacionais, sente-se a ausência de uma maior inserção de tecnologias computacionais e suas vertentes na BNCC, a qual não contempla aspectos de Ciência da Computação, tal como pensamento computacional processo cognitivo utilizado pelo ser humano para desenvolver algoritmos para resolução de problemas. Mesmo ante essa fragilidade apresentada pela BNCC, a utilização de recursos tecnológicos com finalidades pedagógicas e versando o pensamento computacional em instituições de ensino, vem despertando interesse crescente na busca por ferramentas que auxiliem no processo de ensino e aprendizagem. Esse fato gerou um vasto campo multidisciplinar na área da computação, cujo foco está na pesquisa e no desenvolvimento de tais ferramentas - um desses campos é a robótica educativa ${ }^{1}$.

Dentro desse paradigma surgem os drones, equipamentos robóticos (autônomos ou radiocontrolados) em evidência na atualidade, em geral com uma divulgação negativa vinculada ao uso bélico e invasão de privacidade. Assim, a aplicação dos drones como ferramenta de cunho pedagógico é uma área ainda pouco explorada. Os jovens vêm acompanhando o florescer da tecnologia dos drones com bastante entusiasmo, juntamente com os avanços nas demais áreas da robótica e da inteligência artificial. $O$ fato de ter acesso a um equipamento desses em aula, por si só, já tende a tornar a experiência de aprendizado muito mais interessante, o que facilitaria capturar a atenção desse público tão dinâmico e de fácil dispersão, características dos nativos digitais.

Atualmente já existem linguagens de blocos lógicos estilo Scratch $^{2}$ para programar drones (Sattar et al. 2017), além de bibliotecas para diversas linguagens como Java, Python e C, como é o caso da biblioteca DroneKit (Mathias, 2016), o que possibilita seu uso com crianças e adolescentes que tenham pouco ou nenhum contato prévio com programação de computadores e até com alunos de cursos técnicos e de graduação na área de Informática. Isso possibilita o desenvolvimento de atividades diretamente vinculadas à área de Ciência da Computação, mas também seu uso como ferramenta para desenvolvimento de projetos de outras áreas, STEM (acrônimo do Inglês Science,

\footnotetext{
${ }^{1}$ Robótica educativa pode ser definida como uma área do conhecimento que utiliza os conceitos das engenharias e demais ciências no processo de concepção, construção, automação e controle de dispositivos robóticos com propósitos educacionais.

${ }^{2}$ Scratch é uma linguagem de programação visual desenvolvida no MIT, inicialmente pensada para ensino de programação para crianças. É baseada em blocos que podem ser facilmente conectados para compor estruturas lógicas (https://scratch.mit.edu).
} 
Technology, Engineering, and Mathematics) ou não, que possam se valer dos recursos de um equipamento aéreo robótico, programável, geralmente munido de um conjunto de sensores básicos (câmera, acelerômetro, barômetro, giroscópio, entre outros), com possibilidade de comunicação não apenas via radiocontrole, mas também via computador (notebook ou desktop) ou dispositivo mobile.

Os drones, no contexto escolar, possibilitam ao professor a produção de conteúdo que atinja de forma multidisciplinar o currículo de diversas disciplinas e atenda requisitos impostos pela BNCC, pois além de despertar naturalmente o interesse dos alunos, os drones podem ser aplicados, por exemplo, em disciplinas como a Biologia, utilizando recursos de filmagem e fotografia para investigar do alto um determinado ambiente ou hábitat, dando outra perspectiva para os alunos; pode ser utilizado em Matemática para apresentar conceitos de distância, altura, ângulos, trigonometria; pode ser aplicado em aulas de Física para que o aluno adquira conhecimento de conceitos sobre dinâmica do voo, força, empuxo e Leis de Newton; tudo isso com desenvolvimento paralelo de pensamento computacional, necessário para solucionar os problemas propostos pelos professores mediante representação algorítmica.

Além das peculiaridades e possibilidades de se trabalhar no ambiente escolar com uma plataforma de robótica educativa com drones, estes mantêm as características básicas e já validadas da robótica educativa (Khine, 2017; Barker, 2012; Benitti, 2012), promovendo o aprendizado significativo e o desenvolvimento do "saber" e do "saber fazer", mediante aquisição de competências e habilidades para o trabalho em equipe, a colaboração, a liderança, o planejamento, a resolução de problemas, a resolução de conflitos, a análise crítica e a autonomia (entre outras).

\subsection{Contexto atual dos drones na educação}

Segundo Aroca (2012), a robótica educativa já está presente em todas as escolas da rede pública em países como Holanda e Alemanha. Outros países já seguem esse mesmo caminho, como o ocorre na Inglaterra, Itália, Espanha, Canadá e Estados Unidos. $\mathrm{Na}$ América Latina alguns países iniciam suas primeiras tentativas de abrangência nacional, como, por exemplo, o Peru, que, no ano de 2008 chegou à marca de 3.000 (três mil) escolas públicas com aula de robótica educacional. No Brasil esse processo anda ainda timidamente, tendo mais força nas escolas particulares.

Após ampla pesquisa em repositórios e periódicos científicos, foi possível constatar o baixo índice de produções envolvendo drones na educação. Há muito material sobre robótica educativa, entretanto, são raros os que enfocam o uso de drones. Este trabalho é recorte de um trabalho maior, cujo interesse engloba estudos que versem sobre o contexto atual do uso de robótica educativa, currículo com base em robótica educativa, uso de robótica educativa para disciplinas STEM e iniciativas que utilizem drones como tema central no âmbito da robótica educativa. Contudo, aqui serão enfocados especificamente os trabalhos versando sobre drones na robótica educativa para disciplinas STEM.

Foi realizada busca com foco em trabalhos de cunho científico com contribuição relevante para a robótica educativa, com publicação entre 2014 e 2018, período definido com intuito de selecionar os trabalhos mais recentes na área. A pesquisa foi realizada utilizando bases de busca indexadas, incluindo ACM Digital Library, IEEE Xplore Digital Library, Science Direct, Scopus, Banco de Teses e Dissertações da CAPES, Science Research, IOPscience, CiteSeer e Directory of Open Access Journals (DOAJ). Em todas as bases foram utilizadas palavras relacionadas a área da robótica educacional no idioma português e inglês. Estas palavras-chave são: robótica educacional / educativa / pedagógica - educational/pedagogical robotics - robotics - education, com filtragens 
adicionais para trabalhos de interesse com as palavras-chave: drone - UAV - UAS VANT - STEM.

Como critério de inclusão/exclusão, foram considerados somente os trabalhos publicados em periódicos ou conferências com Qualis, dissertações de mestrado ou teses de doutorado, sendo excluídos: os publicados em período anterior a 01 de janeiro de 2014; os que não especificam a forma de coleta dos dados; os que não definem claramente como a robótica está inserida na educação; e, os que não têm o drone como instrumento para disciplinas STEM e sim limitando-se à utilização desses equipamentos para uso externo, visando captura de imagens aéreas (foto ou vídeo) a serem utilizadas como subsídio em aulas de geografia, química, geologia ou educação ambiental (Fombuena, 2017; Palaigeorgiou, Malandrakis e Tsolopani, 2017; Fung e Watts, 2017) ou em disciplinas mais específicas de robótica e controle, onde o próprio drone e sua programação são o foco de estudo (Giernacki et al., 2017; Krajník et al., 2011).

Ao todo, foram selecionados, de forma preliminar, um total de 63 trabalhos para análise, todos versando sobre robótica educativa. Após avaliação com relação aos critérios de inclusão e exclusão, o quantitativo foi reduzido para 18 trabalhos, distribuídos entre 1 tese de doutorado, 4 dissertações de mestrado e 13 artigos em periódicos e proceedings. Desses 18 trabalhos, 5 apresentam como foco o contexto atual da robótica educativa, 9 analisam o uso de robótica educativa no ensino de disciplinas STEM, 3 estudam o currículo para robótica educativa e, por fim, somente 1 deles enfoca efetivamente o uso de drones na robótica educativa.

Entre os trabalhos que avaliam o contexto atual da robótica educacional, avaliase a robótica como uma ferramenta transformadora para o aprendizado, para o pensamento computacional, a codificação e a engenharia, sendo cada vez mais vista como um ingrediente crítico da aprendizagem em áreas STEM na educação básica. Embora a robótica na educação para crianças em idade escolar tenha existido desde o final de 1900 e esteja se tornando mais popular, ela não está bem integrada como uma ferramenta de aprendizado tecnológico em ambientes escolares regulares. De forma geral, todos os estudos obtiveram resultados positivos para o uso de robótica educativa.

Nesse levantamento, o único trabalho encontrado com alguma relevância referente aos drones foi o de Sattar et al. (2017), tendo o drone efetivamente como plataforma de robótica educativa e não apenas como meio de captura de imagens para uso nas disciplinas. Segundo esse estudo, o uso de drones na educação está abrindo novas tendências nas práticas de ensino e aprendizado de uma maneira inovadora e envolvente. $\mathrm{O}$ trabalho busca fornecer uma visão para explorar diferentes tipos de drones e sua compatibilidade para ser usado no ensino de diferentes disciplinas em vários níveis. A investigação centra-se na integração da tecnologia de drones com o conteúdo curricular australiano, como proposta para reforçar a compreensão dos conceitos fundamentais e ajudar a desenvolver o pensamento crítico e o raciocínio no processo de aprendizagem.

Segundo o estudo, os drones podem ser usados em vários ambientes educacionais, e sua inserção na educação oferece enormes benefícios, entre os quais Sattar et al. (2017) destacam: desenvolver uma compreensão profunda (os drones podem ser usados para representar o mesmo problema em diferentes contextos, permitindo que os alunos possam ver os múltiplos aspectos de um problema construindo sua compreensão); motivação e engajamento através da prática (os drones têm o potencial de estimular a motivação e envolver os alunos); conhecimento técnico e habilidade (o uso de drones na educação pode aprimorar o conhecimento técnico e as habilidades de resolução de problemas do aluno, tornando-o competente para lidar com os futuros requisitos técnicos e profissionais); pensamento crítico (os drones oferecem a possibilidade de projetar as tarefas de forma inovadora, através das quais os alunos podem ser desafiados a 
desenvolver habilidades na resolução de problemas, análise, criatividade e pensamento crítico).

Sattar et al. (2017) sugerem que no nível primário do currículo da Austrália, os drones podem ser integrados juntamente com o conteúdo básico. Tarefas básicas podem ser projetadas, como um simples voo, planejamento de rotas, conceitos de direção, ângulo, altura, peso e velocidade. Por exemplo, se a velocidade do drone é conhecida, então o tempo e a distância podem ser calculados. A ideia chave é reforçar o conteúdo com o uso de drones. Nos primeiros anos, os alunos podem desenvolver suas habilidades para manobrar um drone e aplicar os conceitos de ângulos, rotação e altura, exercendo atividades relevantes. Os drones oferecem a possibilidade de projetar atividades de grupo interativas e colaborativas em diferentes áreas de aprendizado definidas pelo currículo australiano, que oferece a oportunidade dos estudantes colaborarem e se comunicarem.

Os drones oferecem uma gama de possibilidades para construir um ambiente centrado na pesquisa e no aluno, através do qual os estudantes desenvolvem ativamente sua compreensão da ciência e ciências sociais, combinando o conhecimento científico com raciocínio e habilidades criticas. Neste contexto, os drones têm um tremendo potencial para ajudar os alunos a aprender conceitos de áreas STEM de uma forma interativa e divertida. Além disso, técnicas e habilidades relacionadas ao cinema e à fotografia podem ser aprendidas com drones. Os alunos também podem ser desafiados com um problema de assistência ao bem-estar humano, gestão ambiental ou gestão econômica/social (Sattar et al., 2017).

\subsection{Iniciativas particulares/comerciais}

Fora da área acadêmica, nota-se o empenho por parte de empresas de drones como a DJI, a Ryze Tech e a Parrot, além de outras da área de brinquedos educativos, como a Makeblock, algumas em parcerias com iniciativas de empresas de desenvolvimento de sistemas, como a Tynker e a DroneBlocks. Entre as iniciativas há o drone Airblock, um kit de robótica educativa que surgiu como uma QuickStarter e está atualmente sendo comercializado pela Makeblock. A Makeblock comercializa diversos kits de robótica educativa, todos modulares, contudo, não foi localizado nenhum estudo científico utilizando a plataforma Airblock que possa validar seu uso do ponto de vista pedagógico.

Segundo os desenvolvedores (Makeblock, 2018), o drone Airblock é a primeira aeronave que usa uma interface gráfica de programação fácil e intuitiva semelhante ao Scratch (Figura 2-a) e um sistema modular para alterar sua configuração, de forma análoga ao Lego, possuindo um módulo central que atua como computador e motores em módulos hexagonais com hélices, que podem ser facilmente encaixados no módulo central por um sistema de conectores e imãs (Figura 2-b). Montado na horizontal, o Airblock se torna um drone com plenas capacidades de voo, contudo, basta mudar a configuração dos módulos e adicionar a base flutuante para transformá-lo em um hovercraft que pode navegar sobre a água. Os desenvolvedores afirmam que a interface gráfica de programação também ajudará o usuário a definir o comportamento do drone e programar suas ações, sendo uma ferramenta divertida para adultos, mas também útil para crianças que podem aprender os fundamentos da programação de maneira simples e imediata. 
(a)

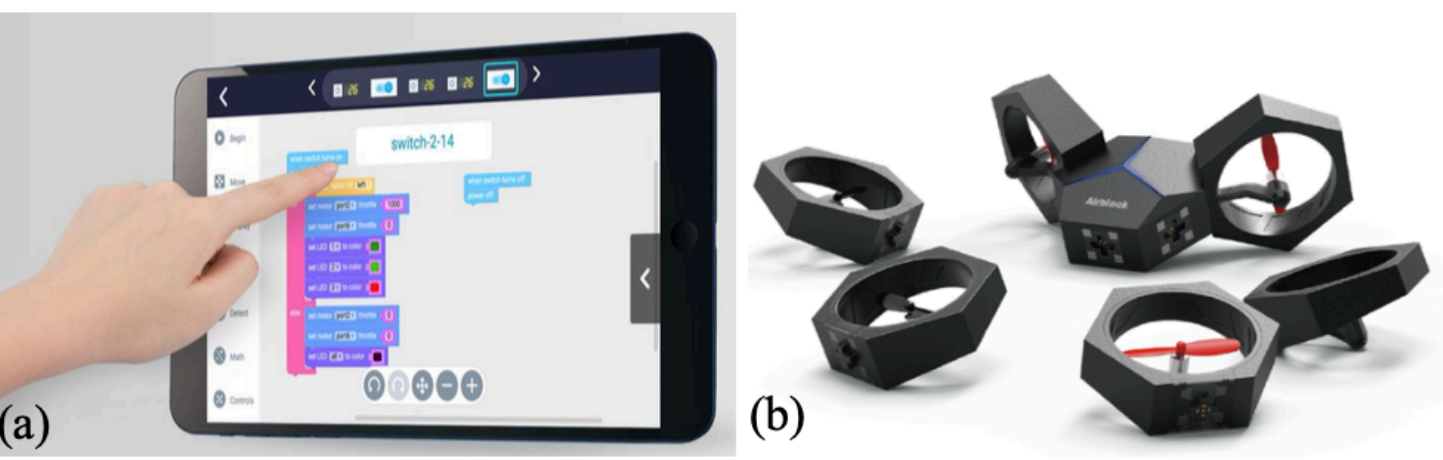

Figura 2 - (a) Makeblock app - o ambiente de programação do Airblock e (b) Drone Airblock com o módulo central e os módulos contendo os motores (Makeblock, 2018)

Uma segunda proposta, segundo Sattar et al. (2017), é o DroneBlocks, baseado no Scratch, que usa os princípios de codificação por blocos lógicos e fornece uma interface fácil de usar, desde que a plataforma robótica (drone) seja compatível. O DroneBlocks foi desenvolvido visando um conjunto de drones comerciais da DJI, entre os quais o DJI Phantom 3, DJI Phantom 4 e o DJI Inspire - atualmente já foram incluídos nessa lista o DJI Mavic e o Tello (Figura 3-b), este último fabricado em parceria da DJI com a startup chinesa Ryze Tech. Os usuários podem planejar o caminho de voo arrastando e soltando blocos na tela para comandar seu drone. Este aplicativo é adequado para iniciantes, podendo ser usado com fins educativos a partir do quarto ano do ensino fundamental.

O DroneBlocks torna a definição das missões do drone acessíveis através de uma interface de programação intuitiva e fácil de usar. Na Figura 3 (a) pode ser vista a interface do DroneBlocks. Para drones munidos de sistema GPS, como os da linha Phantom e Mavic, o DroneBlocks disponibiliza ainda uma interface de visualização de missões, possibilitando que os usuários visualizem a trajetória programada para o drone em um mapa do Google e efetuem alterações, se necessário. O recurso de visualização da missão permite que os usuários entendam se pode haver um erro de código que envie seu drone para fora do curso ou de encontro a um obstáculo.

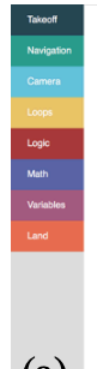

(a)

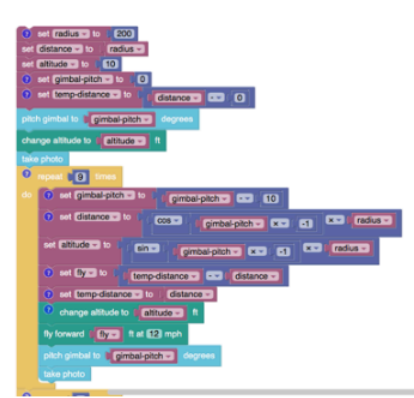

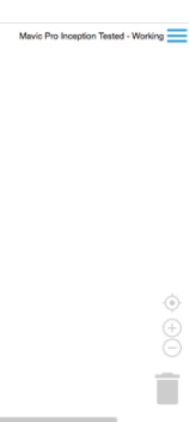

(b)

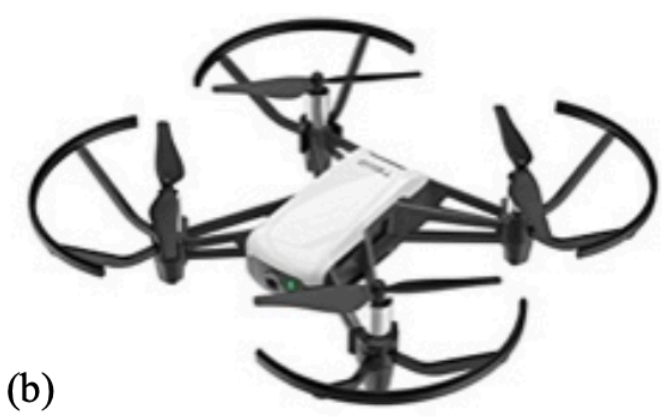

(b)

Figura 3 - (a) Interface do DroneBlocks e (b) Drone Tello (https://dev.droneblocks.io)

Por fim, segundo matéria veiculada pela Tynker (2017) o minidrone Parrot Mambo (Figura 4b) é um drone leve, robusto e fácil de pilotar, mesmo no caso de usuários iniciantes. O drone conta com boa tecnologia, incorporando sensores de alta precisão, o que garante ótima estabilidade. Além dos sensores, dispões de atuadores como o lançador de bolas de plástico e uma garra, o que abre muitas possibilidades de projetos em robótica educativa. O Tynker é uma plataforma de computação criativa (Figura 4a), baseada em blocos lógicos nos mesmos moldes do Scratch, voltada para o ensino de programação para crianças. A plataforma oferece duas interfaces diferentes, uma para o aluno, que 
permite codificar e acessar lições e questionários, e outra para o professor, que possibilita atribuir aulas e monitorar o desempenho dos alunos.
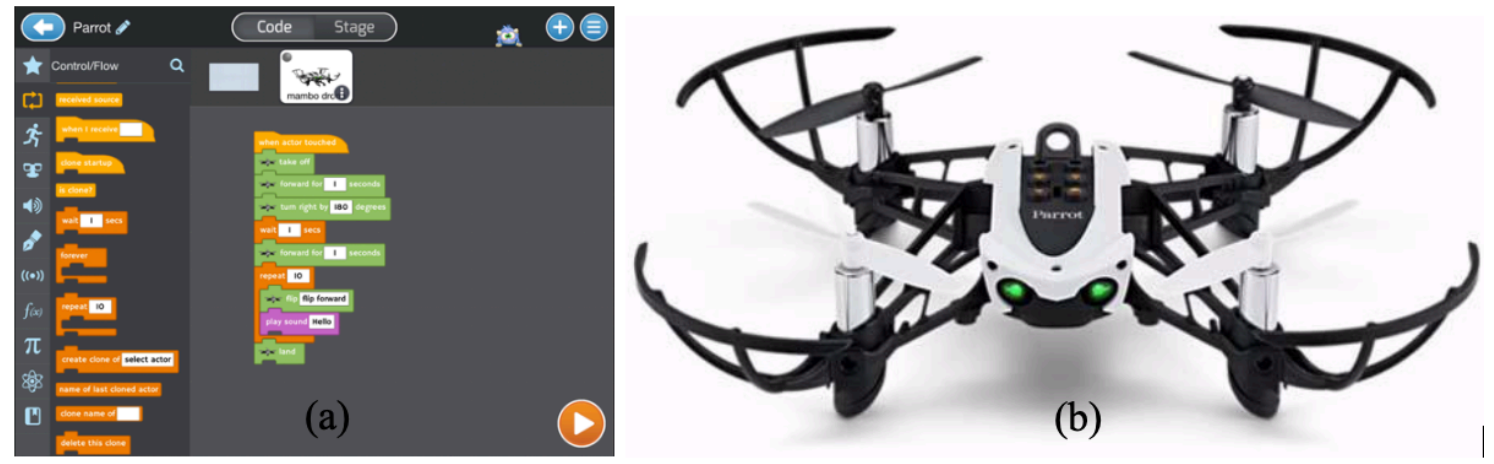

Figura 4 - (a) interface do Tynker e (b) drone Parrot Mambo Drone (https://www.parrot.com/)

As lições de codificação de drone da Tynker oferecem uma abordagem direta e estruturada para que as crianças com idades entre 7 e 14 anos, mesmo aquelas sem experiência prévia, controlem drones em minutos. Novos pilotos podem praticar suas habilidades em um ambiente virtual antes de estarem prontos para executar os comandos em um drone real. O currículo proposto pela Tynker inclui 10 níveis de lições visando o ensino de conceitos de programação. Exemplos de missões incluem (Tynker, 2017): programar a trajetória de voo de um drone da decolagem ao pouso; construir um controlador de drone para pilotar um drone em tempo real; programar inversões, curvas e outras acrobacias aéreas; integrar loops e variáveis para fazer padrões geométricos; criar jogos de codificação como Flappy Drone e drone racing; tirar uma foto aérea e compartilhá-la com amigos ou colegas.

Como é possível observar, há um maior empenho comercial em desenvolvimento de sistemas e equipamentos que vinculem drones à educação do que iniciativas em termos de pesquisas e levantamentos científicos que proponham metodologias e validem esse tipo de equipamentos e suas respectivas possibilidades didáticas. O mercado já detectou esse nicho e está apresentando propostas, quase todas bastante interessantes.

\section{Considerações Finais}

Como visto, há poucas iniciativas relevantes sobre uso de drones na robótica educativa em termos de propostas e pesquisas de caráter científico, devidamente embasadas em aspectos pedagógicos e metodológicos, o que limita bastante este estudo (apesar do interesse em comprovar a carência nessa área). Contudo, na área comercial já despontam algumas iniciativas de diversas empresas, pois essas constataram que os drones, como unidades robóticas ou meramente como brinquedos tecnológicos, além de despertar a curiosidade de jovens e adultos, apresentam uma série de características de alto interesse e impacto para uso com estudantes dos mais diversos níveis de ensino. Falta ainda um maior impulso da área com relação à criação de ferramentas livres. Já existem bibliotecas para programação de controladoras livres baseadas em Arduino ${ }^{3}$, mas exigem do aluno um conhecimento prévio de programação. Há iniciativas portando novos blocos lógicos para o Scratch, permitindo controlar drones comerciais como o Tello, mas ainda bastante limitadas (e vinculadas a um equipamento comercial).

O drone, como uma unidade robótica, apresenta uma grande aplicabilidade para usos em sala de aula, respeitados os critérios de segurança necessários, uma vez que pode

\footnotetext{
${ }^{3}$ Arduino é uma controladora lógica programável de uso geral baseada no paradigma de hardware livre. Há algumas iniciativas de controladoras de voo para drones baseadas nesse paradigma, como é o caso da APM (ArduPilot Mega).
} 
ser programado para resolver os mais diversos tipos de problemas, para as mais diversas áreas e finalidades. Em comparação com uma plataforma tradicional para robótica educativa, munida de robôs terrestres com motores, controladoras e rodas, uma plataforma que contemple o uso de drones abre a possibilidade de resolver problemas que fujam da bidimensionalidade, permitindo literalmente que o aluno dê asas à sua imaginação. Assim, abre-se um leque de possibilidades que vão desde o ensino de conceitos fundamentais de matemática, mecânica e eletrônica, até avançados conceitos de robótica, física e programação, entre tantos outros que podem ser direta ou indiretamente vinculados ao uso de drones como ferramentas de cunho pedagógico, tanto em áreas STEM quanto em outras áreas.

Com base na linha de pensamento apresentada, vislumbra-se a possibilidade de desenvolver ferramentas de subsídio ao ensino de conceitos tais como força, mecânica, pressão, noções de trigonometria, entre outros que poderão ser abordados de forma prática com os alunos, possibilitando também a coleta e análise de dados de sensores (altitude, temperatura, velocidade, latitude/longitude, pressão do ar etc.). Assim, os alunos poderiam aprender sobre as mudanças envolvidas no voo e explorar temas como Princípio de Bernoulli, Leis de Newton, velocidade, aceleração, força, massa, empuxo, arrasto, pressão, densidade, enfim, além de conceitos físicos e matemáticos do voo, teriam acesso diferenciado à noções de mecânica, eletrônica, ética e implicações legais (já que drones estão nesse foco atualmente).

Pelas suas características, o uso de ferramentas vinculadas à computação e robótica educativas, tendem a despertar o interesse de crianças e adolescentes para prosseguir seus estudos em áreas vinculadas à tecnologia, como cursos de física, matemática, engenharias e computação, áreas com carência de formação profissional para atender a crescente demanda. De forma natural, esse tipo de tecnologia pedagógica tem maior influência nas disciplinas STEM, diretamente vinculadas a área de Exatas, buscando tornar essas disciplinas mais atraentes e menos "complexas" para os alunos.

Por fim, chega-se à conclusão de que os drones apresentam um imenso potencial de integração com os conteúdos curriculares, permitindo reforçar a sua compreensão e ajudando a desenvolver o pensamento crítico e o raciocínio. Atualmente, a possibilidade de uso de drones nas escolas é vista de forma positiva, o que é acompanhado pelo pensamento geral dos professores. Os drones e outras tecnologias relacionadas podem desempenhar um papel importante para envolver melhor os alunos na sala de aula.

\section{Referências bibliográficas}

AROCA, Rafael Vidal. Plataforma robótica de baixíssimo custo para robótica educacional. Tese de doutorado - Programa de Pós-Graduação em Engenharia Elétrica e de Computação da UFRN. Natal: UFRN, 2012.

BARKER, Bradley S. (Ed.). Robots in K-12 education: A new technology for learning. IGI Global, 2012.

BENITTI, Fabiane Barreto Vavassori. Exploring the educational potential of robotics in schools: A systematic review. Computers \& Education, v. 58, n. 3, p. 978-988, 2012.

BRASIL. Ministério da Educação. Secretaria da Educação Básica. Base nacional comum curricular - Ensino Médio. Brasília, DF, 2017. Disponível em: <http://basenacionalcomum.mec.gov.br/>. Acesso em: 18 jun. 2018.

FOMBUENA, Arnau. Unmanned Aerial Vehicles and Spatial Thinking: Boarding Education With Geotechnology And Drones. in IEEE Geoscience and Remote Sensing Magazine, v. 5, n. 3, p. 8-18, Sept. 2017. 
FRANÇA, Rozelma; TEDESCO, Patrícia. Pensamento computacional sob a perspectiva de licenciandos em computação. In: Anais do Workshop de Informática na Escola. 2017. p. 795.

FUNG, F. M.; WATTS, S. The Application of Drones in Chemical Education for Analytical Environmental Chemistry. in Teaching and the Internet: The Application of Web Apps, Networking, and Online Tech for Chemistry Education. ACS, 2017.

GIERNACKI, Wojciech et al. Crazyflie 2.0 quadrotor as a platform for research and education in robotics and control engineering. In: 22nd International Conference on Methods and Models in Automation and Robotics (MMAR). IEEE, 2017. p. 37-42.

HASSANALIAN, Mostafa; ABDELKEFI, Abdessattar. Classifications, applications, and design challenges of drones: A review. Progress in Aerospace Sciences, v. 91, p. 99-131, 2017.

KHINE, Myint Swe. Robotics in STEM Education: Redesigning the Learning Experience. Springer, 2017.

KRAJNÍK, Tomáš; VONÁSEK, V.; FISER, D.; FAIGL, J. AR-drone as a platform for robotic research and education. in International conference on research and education in robotics. Springer, Berlin, Heidelberg, 2011. p. 172-186.

LUPPICINI, Rocci; SO, Arthur. A technoethical review of commercial drone use in the context of governance, ethics, and privacy. Technology in Society, v. 46, p. 109-119, 2016.

MAKEBLOCK. Airblock: modular and programmable flying robot. 2018. Disponível em: <https://www.makeblock.com>. Acesso em: 12 abr 2018.

MATHIAS, H. David. An autonomous drone platform for student research projects. Journal of Computing Sciences in Colleges, v. 31, n. 5, p. 12-20, 2016.

PALAIGEORGIOU, George; MALANDRAKIS, George; TSOLOPANI, Christine. Learning with Drones: flying windows for classroom virtual field trips. In: IEEE 17th International Conference on Advanced Learning Technologies (ICALT). Timisoara: IEEE, 2017. p. 338-342.

SATTAR, Farha; TAMATEA, Laurence; NAWAZ, Muhammad. Droning the Pedagogy: Future Prospect of Teaching and Learning. in International Journal of Educational and Pedagogical Sciences, v. 11, n. 6, p. 1632-1637, 2017.

SILVA, Cláudia Regina de Sousa e; YEPES, Igor. Desenvolvimento de sistema SLAM com odometria visual para VANT de inspeção em ambientes internos. Humanidades \& Inovação, [S.1.], june 2016. ISSN 2358-8322.

TYNKER. Tynker and Parrot launch "Parrot Mambo Code" - All-in-one bundle to teach kids to program Parrot drones. 2017. Disponível em: <https://www.tynker.com/about/press/2017/08-tynker-and-parrot-launch-parrot-mambo -code-all-in-one-bundle-to-teach-kids-to-program-parrot>. Acesso em: 15 abr 2018.

WARE, Jared. Teaching with Drones: The Challenges and the Opportunities. 2017. Disponível em: < https://www.asprs.org/wp-content/uploads/2018/03/12-17-SI.pdf> Acesso em: 12 ago 2018.

ZHAO, Weihua; GO, Tiauw Hiong. Quadcopter formation flight control combining MPC and robust feedback linearization. Journal of the Franklin Institute, v. 351, n. 3, p. 1335-1355, 2014. 